Check for updates

Cite this: Chem. Sci., 2018, 9, 8127

๑ All publication charges for this article have been paid for by the Royal Society of Chemistry

\title{
Gold-catalyzed conversion of lignin to low molecular weight aromatics $\uparrow$
}

\author{
Yang Song, (D) ab Justin K. Mobley, (D) $\dot{t}^{\mathrm{c}}$ Ali Hussain Motagamwala, ${ }^{\mathrm{cd}}$ Mark Isaacs, $\S \mathbf{q}^{\mathrm{e}}$ \\ James A. Dumesic, ${ }^{\text {cd }}$ John Ralph, (D) ${ }^{\text {cf }}$ Adam F. Lee, (D) Karen Wilson ${ }^{g}$ \\ and Mark Crocker (D) *ab
}

\begin{abstract}
A heterogeneous catalyst system, employing Au nanoparticles (NPs) and Li-Al (1:2) layered double hydroxide (LDH) as support, showed excellent activity in aerobic oxidation of the benzylic alcohol group in $\beta-O-4$ linked lignin model dimers to the corresponding carbonyl products using molecular oxygen under atmospheric pressure. The synergistic effect between Au NPs and the basic Li-Al LDH support induces further reaction of the oxidized model compounds, facilitating facile cleavage of the $\beta-O-4$ linkage. Extension to oxidation of $\gamma$-valerolactone (GVL) extracted lignin and kraft lignin using Au/Li-Al $\mathrm{LDH}$ under similar conditions produced a range of aromatic monomers in high yield. Hydrolysis of the $\mathrm{Au} / \mathrm{Li}-\mathrm{Al}$ LDH oxidized lignin was found to increase the degree of lignin depolymerization, with monomer yields reaching $40 \%$ for GVL extracted lignin. Based on these results, the Au/Li-Al LDH $+\mathrm{O}_{2}$ catalyst system shows potential to be an environmentally friendly means of depolymerizing lignin to low molecular weight aromatics under mild conditions.
\end{abstract}

Received 19th July 2018

Accepted 24th August 2018

DOI: $10.1039 / \mathrm{c} 8 \mathrm{sc} 03208 \mathrm{~d}$

rsc.li/chemical-science grain ethanol, ${ }^{3}$ the utilization of lignin is limited, ${ }^{2}$ despite the fact that the cellulosic ethanol production cost is directly correlated to the valorization of lignin., ${ }^{4,5}$ Enzyme-induced combinatorial radical polymerization of monolignols leaves lignin with a complex, amorphous chemical structure.$^{6-8}$ In view of its structural complexity, harnessing this resource requires chemical transformations that can depolymerize this recalcitrant material to useable monomers with high efficiency and selectivity. ${ }^{9}$ Although lignin possesses a heterogeneous structure, all lignins contain the alkyl aryl ether unit (i.e., contain the $\beta$-O-4 linkage) as the most abundant structural unit (up to $60 \%$ of all linkages $)^{8}$ followed by $\beta-5, \beta-\beta$, and other minor units (Fig. 1).

Although much effort has been invested in hydrogenolytic approaches to lignin depolymerization, the chemistry can be non-selective; ${ }^{10}$ moreover, most phenolics produced via reductive pathways would face competition from the low cost

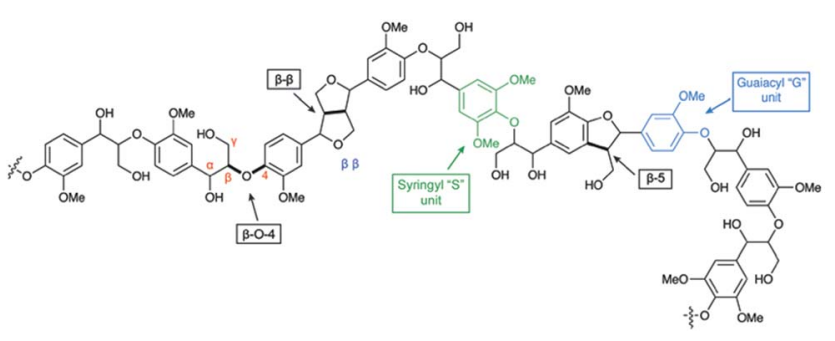

Fig. 1 Structural representation of a lignin fragment illustrating selected linkages. 
phenolics produced from petroleum. ${ }^{11}$ Compared to hydrogenolytic methods, catalytic oxidative lignin depolymerization is desirable as the products exhibit increased functionalization and complexity, ${ }^{\mathbf{1 1}-13}$ otherwise not readily available from petroleum resources. ${ }^{6}$ Many recent studies utilize homogenous catalytic systems for oxidative lignin depolymerization, and while promising results have been achieved for lignin model compounds, many systems suffer from a lack of selectivity, ${ }^{\mathbf{1 0 , 1 4}}$ catalyst decomposition, ${ }^{12}$ and the requirement for harsh reaction conditions. ${ }^{15}$ In addition, problems inherent in the recycling of homogenous catalysts make the industrial application of these systems difficult. Heterogeneous catalyst systems are generally better suited for industrial applications, ${ }^{\mathbf{1 6}}$ and recent reports have shown moderate to high yields in heterogeneously catalyzed oxidation of lignin model compounds and monoaromatic substrates, ${ }^{17-23}$ albeit with few successful examples of lignin depolymerization having been reported. Aside from catalyst type, the oxidant is another key factor in oxidative lignin depolymerization processes, molecular oxygen being favored as the terminal oxidant for any large scale oxidative conversion process. ${ }^{17,24}$ In the past 20 years, Au nanoparticles (NPs) supported on metal oxide and layered double hydroxide (LDH) supports $\left(\mathrm{Au} / \mathrm{TiO}_{2}, \mathrm{Au} / \mathrm{CeO}_{2}, \mathrm{Au} / \mathrm{Mg}-\mathrm{Al} \mathrm{LDH}, \mathrm{Au} / \mathrm{Ni}-\mathrm{Al} \mathrm{LDH}\right.$, etc.) have been shown to selectively catalyze aerobic oxidations of alcohols to the corresponding carbonyl compounds. ${ }^{25-29}$ Herein, we introduce a heterogeneous catalyst system for the aerobic oxidation and depolymerization of lignin by targeting the lignin $\beta$-aryl ether fragment, utilizing Au NPs supported on a basic $\mathrm{Li}-\mathrm{Al} \mathrm{LDH}^{30}$ under molecular oxygen at atmospheric pressure. We highlight the high oxidation activity of $\mathrm{Au} / \mathrm{Li}-\mathrm{Al}$ LDH with a variety of lignin model compounds, and its applicability towards lignin depolymerization.

\section{Results and discussion}

Our initial studies focused on the oxidation of simple benzylic alcohols (Tables 1 and 2). Encouragingly, we found that by employing a strongly basic $\mathrm{Li}-\mathrm{Al}(1: 2) \mathrm{LDH}^{30}$ as support, the activity for benzylic alcohol oxidation increased significantly compared to less basic $\mathrm{Au} / \mathrm{LDH}$ catalysts. When toluene was

Table 1 Oxidation of 1-phenylethanol to acetophenone using Au/ $\mathrm{LDHs}^{a}$

\begin{tabular}{lllll}
\hline Catalyst & $t[\mathrm{~h}]$ & Conv. $^{b}[\%]$ & Sel. $^{b}[\%]$ & TOF $^{c}\left[\mathrm{~h}^{-1}\right]$ \\
\hline $\mathrm{Au} / \mathrm{Mg}-\mathrm{Al} \mathrm{LDH}$ & 1 & 75 & $>99$ & 5926 \\
$\mathrm{Au} / \mathrm{Ni}-\mathrm{Al} \mathrm{LDH}$ & 1 & 34 & $>99$ & 1317 \\
$\mathrm{Au} / \mathrm{Li}-\mathrm{Al} \mathrm{LDH}$ & 1 & 98 & $>99$ & $11061(29708)^{d}$
\end{tabular}

a 1-Phenylethanol (1 mmol), catalyst ( $0.1 \mathrm{~g}, 1 \mathrm{wt} \% \mathrm{Au})$, diphenyl ether $(10 \mathrm{~mL}), 80^{\circ} \mathrm{C}, p=1 \mathrm{~atm} . \mathrm{O}_{2}\left(10 \mathrm{~mL} \min ^{-1}\right) .{ }^{b}$ Conversion and selectivity were determined by GC-MS using dodecane as internal standard. ${ }^{c}$ TOF values are based on the number of surface Au atoms calculated for the mean $\mathrm{Au}$ particle size found via TEM analysis (see ESI Fig. S3). ${ }^{33,34} d$ TOF in parentheses was determined using toluene as solvent. Note: a control experiment conducted without catalyst showed no conversion.
Table 2 Aerobic oxidation of simple benzylic alcohols using $\mathrm{Au} / \mathrm{Li}-\mathrm{Al}$ $\mathrm{LDH}^{a}$

\begin{tabular}{|c|c|c|c|c|c|}
\hline Entry & Substrate & $t[\mathrm{~h}]$ & Conv. [\%] & Product & Sel. [\%] \\
\hline 1 & & 4 & 80 & & 78 \\
\hline 2 & & 2 & 98 & & 98 \\
\hline 3 & & 0.5 & $>99$ & & $>99$ \\
\hline 4 & & 2 & 67 & & $>99$ \\
\hline 5 & & 4 & 80 & & $>99$ \\
\hline $6^{b}$ & & 2 & $>99$ & & $>99$ \\
\hline 7 & & 0.5 & $>99$ & & $>99$ \\
\hline
\end{tabular}

${ }^{a}$ Substrate ( $\left.1 \mathrm{mmol}\right), \mathrm{Au} / \mathrm{Li}-\mathrm{Al} \mathrm{LDH}(50 \mathrm{mg}, 1 \mathrm{wt} \% \mathrm{Au})$, diphenyl ether (DPE, $10 \mathrm{~mL}), 80^{\circ} \mathrm{C}, p=1 \mathrm{~atm} . \mathrm{O}_{2}\left(10 \mathrm{~mL} \mathrm{~min}{ }^{-1}\right)$. Conversion and selectivity were determined by GC-MS using dodecane as internal standard. ${ }^{b}$ Substrate $(1 \mathrm{mmol}), \mathrm{Au} / \mathrm{Li}-\mathrm{Al} \mathrm{LDH}(50 \mathrm{mg}, 1 \mathrm{wt} \% \mathrm{Au})$, diphenyl ether (DPE, $10 \mathrm{~mL}), 100{ }^{\circ} \mathrm{C}, p=1 \mathrm{~atm} . \mathrm{O}_{2}\left(10 \mathrm{~mL} \mathrm{~min}{ }^{-1}\right)$. Conversion and selectivity were determined by GC-MS using dodecane as internal standard. Partial results shown, for full list of benzylic alcohols tested refer to ESI (see ESI Table S2).

used as solvent for comparison with literature data, $\mathrm{Au} / \mathrm{Li}-\mathrm{Al}$ LDH exhibited the highest turnover frequency (TOF) compared to other supported $\mathrm{Au}$ NP catalyst systems that effectively oxidize 1-phenylethanol such as Au/Mg-Al LDH $\left(3213 \mathrm{~h}^{-1}\right){ }^{31}$ $\mathrm{Au} / \mathrm{Ni}-\mathrm{Al} \mathrm{LDH}\left(5310 \mathrm{~h}^{-1}\right),{ }^{32}$ and $\mathrm{Au} / \mathrm{Al}_{2} \mathrm{O}_{3}\left(825 \mathrm{~h}^{-1}\right) .^{27}$

The high oxidation activity of $\mathrm{Au} / \mathrm{Li}-\mathrm{Al} \mathrm{LDH}$ can be explained by the degree of charge transfer from the basic support to the $\mathrm{Au}$ NPs. ${ }^{30,35}$ According to $\mathrm{CO}_{2}$ pulse chemisorption measurements, the basic site concentration follows the order $\mathrm{Mg}-\mathrm{Al} \mathrm{LDH}$

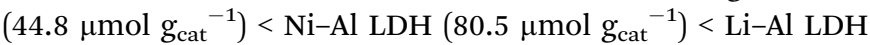
(102.7 $\left.\mu \mathrm{mol} \mathrm{g}_{\text {cat }}{ }^{-1}\right)$, while evidence of charge transfer to the supported Au NPs was provided by X-ray photoelectron spectroscopy (XPS): as the basicity of the support increases, the binding energy of the Au $4 f_{7 / 2}$ peak is shifted towards lower energy (see Fig. S1 and S2 in ESI†).

Besides the basic nature of the $\mathrm{Li}-\mathrm{Al} \mathrm{LDH}$, the $\mathrm{Au}$ nanoparticle size also plays an important role. It has been well established that reactivity towards alcohol oxidation using Au NPs decreases significantly when the Au particle size surpasses $5 \mathrm{~nm} ;^{36-39}$ we observe via transmission electron microscopy (TEM) that most of the Au NPs in our catalyst are $<5 \mathrm{~nm}$, the median particle size being $2.1 \mathrm{~nm}$ (Fig. S3†), which should be optimal for alcohol oxidation. The $\mathrm{Li}-\mathrm{Al} \mathrm{LDH}$ used in this catalyst system possesses a crystalline structure (Fig. S4†) and exhibits a characteristic sand rose morphology (Fig. S5†) with a relatively high surface area of $85 \mathrm{~m}^{2} \mathrm{~g}^{-1}$ (Table $\mathrm{S} 1 \dagger$ ), which favors adsorption of the alcohol and facilitates the formation of small Au NPs on the catalyst surface. 
The difficulty of activating $\mathrm{O}_{2}$ represents one of the rate limiting factors in oxidation catalysis. ${ }^{40}$ It is contended that $\mathrm{Au}$ NPs adsorbed on the surface of a basic support contain coordinatively unsaturated $\mathrm{Au}$ atoms that are efficient in $\mathrm{O}_{2}$ dissociation, and the activity of adsorbed $\mathrm{O}_{2}$ on metallic Au follows Brønsted acid-base reaction patterns. ${ }^{38,40}$ Our proposed mechanism (Fig. 2) suggests that catalysis occurs at the $\mathrm{Au}-\mathrm{O}-\mathrm{Li}$ interface. Electron rich Au NPs activate molecular oxygen via electron donation to the LUMO $\left(\pi^{*}\right)$ of $\mathrm{O}_{2}$ (ref. 41 ) and simultaneously, the support deprotonates the benzylic hydroxyl group to allow adsorption to the catalyst surface. The oxidation process is then completed by a series of deprotonation, elimination, and catalyst regeneration steps. It should also be noted that the reaction proceeds via a two-electron pathway, as evidenced by the selective oxidation of $\alpha$-cyclopropylbenzenemethanol without ring opening (entry 6 in Table 2). Compared to radical pathways, a two-electron oxidation mechanism preserves desirable aromaticity in most products, and prevents repolymerization of intermediates that generate oligomers via irreversible bond formation. ${ }^{42-44}$

The properties of $\mathrm{Au} / \mathrm{Li}-\mathrm{Al} \mathrm{LDH}$ in aerobic oxidation were further evaluated using a lignin model dimer, 2a, containing the $\beta$-O-4 interunit linkage (Fig. 3). Our catalyst system showed selective oxidation of the secondary benzylic alcohol in $2 \mathbf{a}$ with a reaction rate of $10.8 \mathrm{mmol} \mathrm{h}^{-1} \mathrm{~g}_{\text {cat }}{ }^{-1}$, achieving a $37 \%$ yield of $2 \mathbf{b}$ in $5 \mathrm{~h}$ with $68 \%$ conversion of $\mathbf{2 a}$ (near complete conversion of $2 \mathbf{a}$ was seen after $24 \mathrm{~h}$ ). Under these conditions $2 \mathbf{b}$ reacted further to give the dehydration product $2 \mathrm{c}$ (rate $=3.6 \mathrm{mmol} \mathrm{h}^{-1}$ $\mathrm{g}_{\text {cat }}{ }^{-1}$ ) and the retro-aldol product $2 \mathrm{~d}$ (rate $=36 \mathrm{mmol} \mathrm{h}^{-1}$ $\mathrm{g}_{\text {cat }}{ }^{-1}$ ). The high reaction rate of the retro-aldol product formation may be attributed to the basic property of the $\mathrm{Li}-\mathrm{Al}$

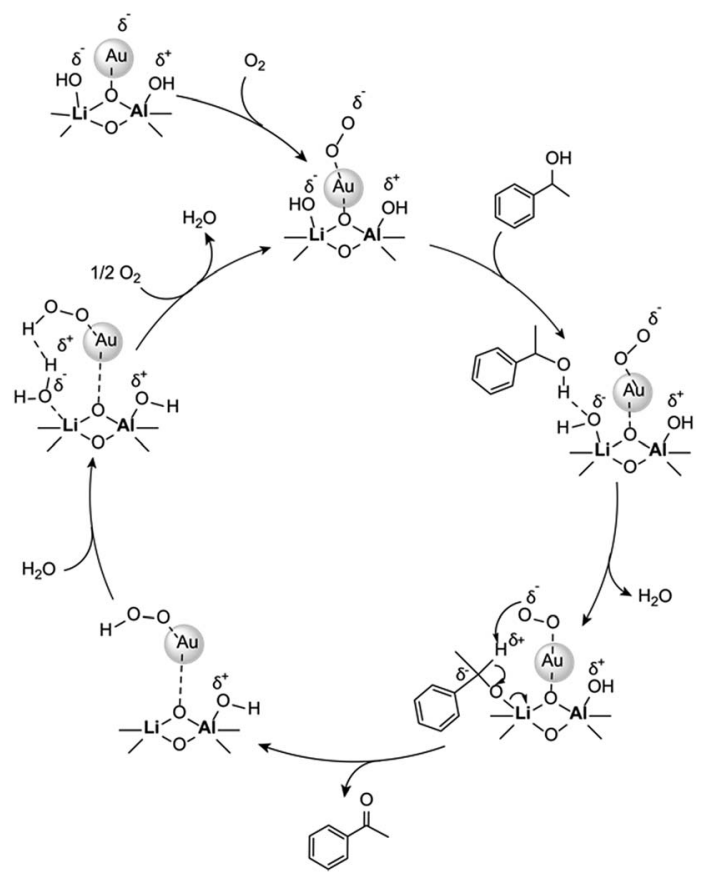

Fig. 2 Proposed mechanism for aerobic oxidation of benzylic alcohols over Au/Li-Al LDH.
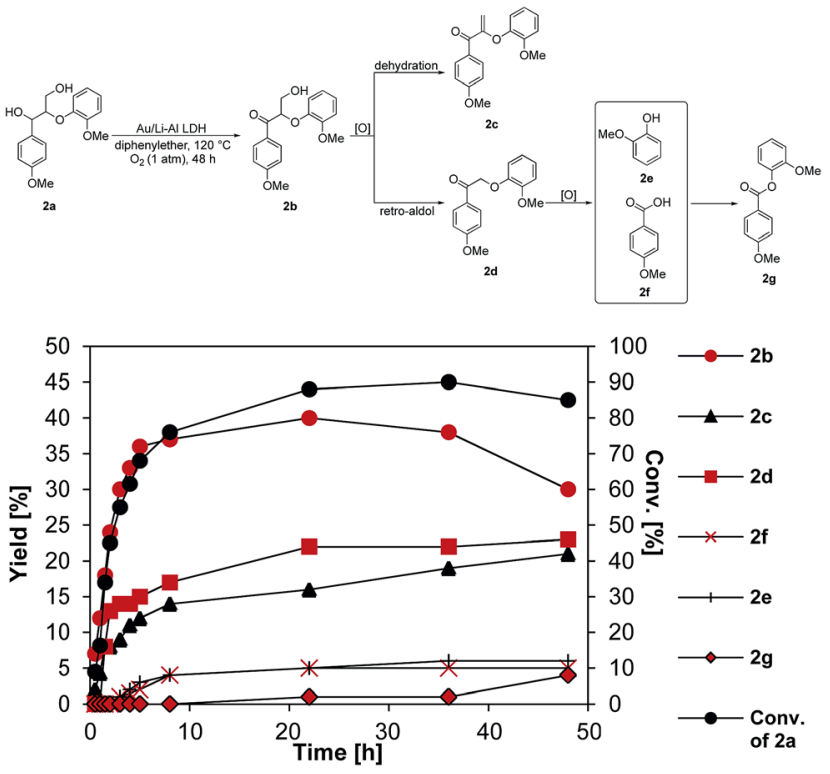

Fig. 3 Aerobic oxidation of lignin model dimer 2a using Au/Li-Al LDH. Conditions: substrate ( $1 \mathrm{mmol}), \mathrm{Au} / \mathrm{Li}-\mathrm{Al}$ LDH $(0.1 \mathrm{~g}, 1 \mathrm{wt} \% \mathrm{Au}$ ), DPE (10 $\mathrm{mL}), 120{ }^{\circ} \mathrm{C}, p=1 \mathrm{~atm} . \mathrm{O}_{2}\left(10 \mathrm{~mL} \mathrm{~min}^{-1}\right)$. All reaction rates were obtained by oxidizing the individual intermediates using the same conditions. For full details refer to ESI (Fig. S5-S7 in ESI†). Conversion and yields were determined by GC-MS using dodecane as internal standard.

support, such reactions having been reported in the literature. ${ }^{45,46}$ While $2 \mathrm{c}$ was not observed to react further (Fig. S6 $\dagger$ ), $2 \mathrm{~d}$ reached a maximum yield of $40 \%$ after $24 \mathrm{~h}$, in turn producing guaiacol (2e) and $p$-anisic acid (2f) at a rate of $10.8 \mathrm{mmol} \mathrm{h}^{-1}$ $\mathrm{g}_{\text {cat }}{ }^{-1}$. Formation of products $2 \mathrm{e}$ and $2 \mathrm{f}$ via cleavage of the $\beta-\mathrm{O}-4$ bond in 2d using molecular oxygen has also been observed in various literature reports. ${ }^{4-49}$ Indeed, the propensity of the oxidized (ketone) form of $\beta$-O-4 model compounds to undergo oxidative cleavage to monomers has been attributed to the significantly weaker $\mathrm{C}-\mathrm{O}$ bond present in the ketone form compared to the initial benzylic alcohol compound, and a decrease in $\mathrm{p} K_{\mathrm{a}}$ of the proton located at $\mathrm{C}_{\beta}{ }^{48,50}$ Schoenebeck and coworkers ${ }^{49}$ suggested that the first step would most likely involve the formation of an enolate intermediate after deprotonation of the $\mathrm{C}_{\beta}-\mathrm{H}$, which can be further oxidized to give a hydroperoxide species. Thereafter, two possible routes would give products 2e and 2f: (1) an anionic pathway involving formation of a dioxetane intermediate, which could undergo subsequent fragmentation to a carboxylate and a phenyl ester; (2) a homolytic O-O scission step forms an O centred radical, which undergoes further $\mathrm{C}-\mathrm{C}$ cleavage, as suggested by Wang and co-workers. ${ }^{47}$

In a subsequent esterification reaction, $2 \mathbf{e}$ and $\mathbf{2 f}$ reacted to form $2 \mathrm{~g}$ with a rate of $5.4 \mathrm{mmol} \mathrm{h}^{-1} \mathrm{~g}_{\text {cat }}{ }^{-1}$. A similar rate of product formation was observed when only the Li-Al LDH support was used, consistent with base catalyzed esterification. Although esterification is an undesirable side-reaction, the ester linkage in $2 \mathrm{~g}$ can be cleaved by means of simple hydrolysis, which, when translated to lignin, would result in net cleavage of the $\beta$-aryl ether linkage. 
In order to examine the reusability of $\mathrm{Au} / \mathrm{Li}-\mathrm{Al} \mathrm{LDH}$ under these reaction conditions, recycle reactions were carried out using a slightly simpler model compound, 3a (Table S3 and $\mathrm{S} 4 \dagger$ ). After three runs, the conversion of $3 \mathrm{a}$ measured at $4 \mathrm{~h}$ showed no change $(\sim 58 \%)$. However, for recycle experiments performed at longer reaction times $(16 \mathrm{~h})$, a gradual decrease in the yields of $2 \mathbf{e}$ and $\mathbf{2 f}$, formed from $2 \mathbf{d}$, was apparent. Yields of $\mathbf{2 e}, \mathbf{2 f}$, and $2 \mathrm{~g}$ were largely restored after the spent catalyst was washed with water at room temperature ( $4^{\text {th }}$ run in Table S4 $\dagger$ ), consistent with the removal of adsorbed $2 \mathbf{e}$ and $2 \mathbf{d}$ (identified in the water washings). This indicates that over time $\mathbf{2 e}$ and $\mathbf{2 d}$ accumulate on the catalyst surface, as would be expected for acidic compounds, slowing the further conversion of $\mathbf{2 d}$. Leaching of the catalytically active species into the reaction medium is an underlying concern for heterogeneously catalyzed lignin depolymerization, as observed by Bolm and coworkers. ${ }^{17}$ In the present work, when $\mathrm{Au} / \mathrm{Li}-\mathrm{Al} \mathrm{LDH}$ was removed via hot filtration after $2 \mathrm{~h}$ of oxidation of $\mathbf{2 a}$, no further conversion was observed after an additional $10 \mathrm{~h}$ reaction time. Consistent with these findings, concentrations of $\mathrm{Au}, \mathrm{Li}$, and $\mathrm{Al}$ in solution were determined to be $<0.1 \mathrm{ppm}$ by ICP-OES.

Next, our focus shifted to the use of process lignins, namely, Indulin AT kraft lignin (softwood, from pine) and $\gamma$-valerolactone extracted lignin ${ }^{51}$ from maple wood (hereafter referred to as KL and GVL, respectively), as substrate. Reaction conditions similar to those used in the lignin model compound experiments were applied, albeit dimethylformamide (DMF) was used as solvent instead of DPE due to the higher solubility of lignin in DMF. Fig. 4 shows 2D HSQC NMR spectra comparing KL and GVL before and after oxidation with $\mathrm{O}_{2}$ in the presence of $\mathrm{Au} / \mathrm{Li}-\mathrm{Al} \mathrm{LDH}$ (oxidized KL and GVL are abbreviated as $\mathrm{KL}_{\mathrm{ox}}$ and $\mathrm{GVL}_{\mathrm{ox}}$, respectively).

Analysis of the oxygenated aliphatic region of $\mathrm{GVL}_{\mathrm{ox}}$ and $\mathrm{KL}_{\mathrm{ox}}$ revealed the absence of signals corresponding to $\beta$-aryl ether (A) and phenylcoumaran (B) units, albeit compared to $\mathrm{KL}_{\mathrm{ox}}$, some resinol (C) remains in $\mathrm{GVL}_{\mathrm{ox}}$. It is hypothesized that as for the $\beta$ aryl ether model dimer $\mathbf{2 a}$, the $\beta$-aryl ether units in lignin may have gone through a similar oxidation-cleavage-re-coupling process forming the ester moiety, which has no sidechain $\mathrm{C}-\mathrm{H}$ signals to observe via 2D HSQC NMR. Moreover, cross peaks correlating to the guaiacyl (G) units are no longer present in the HSQC spectrum after oxidation of $\mathrm{KL}$ and GVL $\left(\mathrm{KL}_{\mathrm{Ox}}\right.$ and $\mathrm{GVL}_{\mathrm{ox}}$ ), and vanillate (VA) analogs are the only remaining signals for both. Additionally, the HSQC spectrum of $\mathrm{GVL}_{\mathrm{ox}}$ displayed a significant decrease in syringyl (S) and an increase in oxidized syringyl units $\left(\mathbf{S}^{\prime}\right)$.

The oxidized lignin samples were next subjected to hydrolysis with $\mathrm{NaOH}(0.1 \mathrm{M})$, after which the mixture was neutralized with $\mathrm{HCl}(1 \mathrm{M})$ and the soluble material was extracted with ethyl acetate (EtOAc). $\mathrm{KL}_{\mathrm{ox}}$ yielded $20 \mathrm{wt} \%$ of EtOAc soluble material after hydrolysis (Fig. 5A), which is double the amount obtained from the initial oxidized lignin sample. Notably, $\mathrm{GVL}_{\mathrm{ox}}$ after hydrolysis afforded $56 \mathrm{wt} \%$ EtOAc soluble material, versus $20 \mathrm{wt} \%$ without the additional hydrolysis step (Fig. 5A). The low percentage of soluble organic products formed from $\mathrm{KL}_{\mathrm{ox}}$ is not surprising given that the kraft pulping process is known to
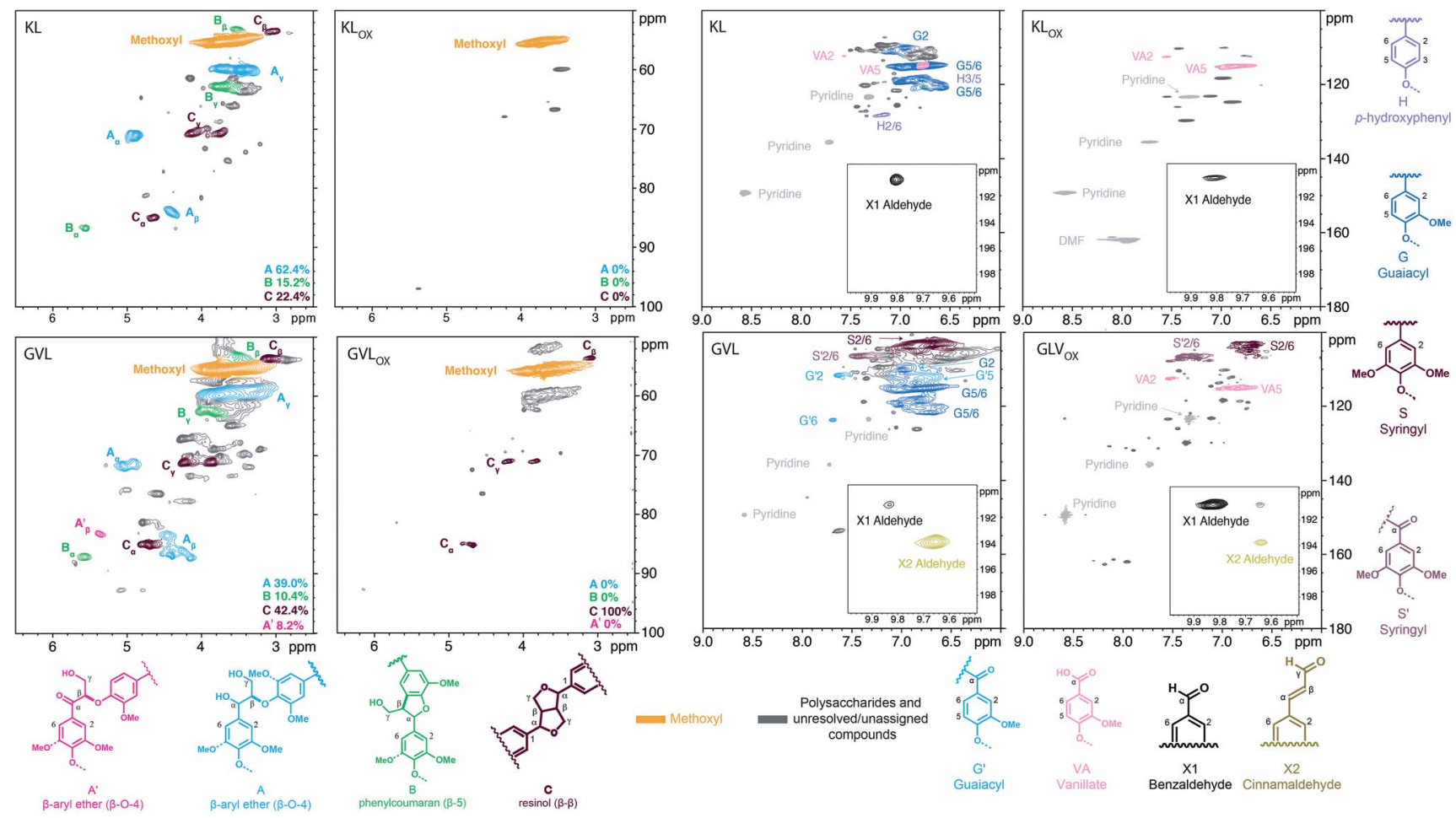

Fig. 4 2D HSQC NMR spectra of $\mathrm{KL}, \mathrm{KL}_{\mathrm{ox}}, \mathrm{GVL}$, and $\mathrm{GVL}_{\mathrm{ox}}$ lignin. All samples dissolved in 4 : $1 \mathrm{DMSO}$-d6/pyridine-d5; contours color-coded to structures responsible; percentages are determined from volume integrals based on $\alpha_{\mathrm{C}-\mathrm{H}}$ with the exception of $A^{\prime}$ which uses the $\beta_{\mathrm{C}-\mathrm{H}}$ signal. The assignment of peaks is based on known lignin spectra and available model compound data. 

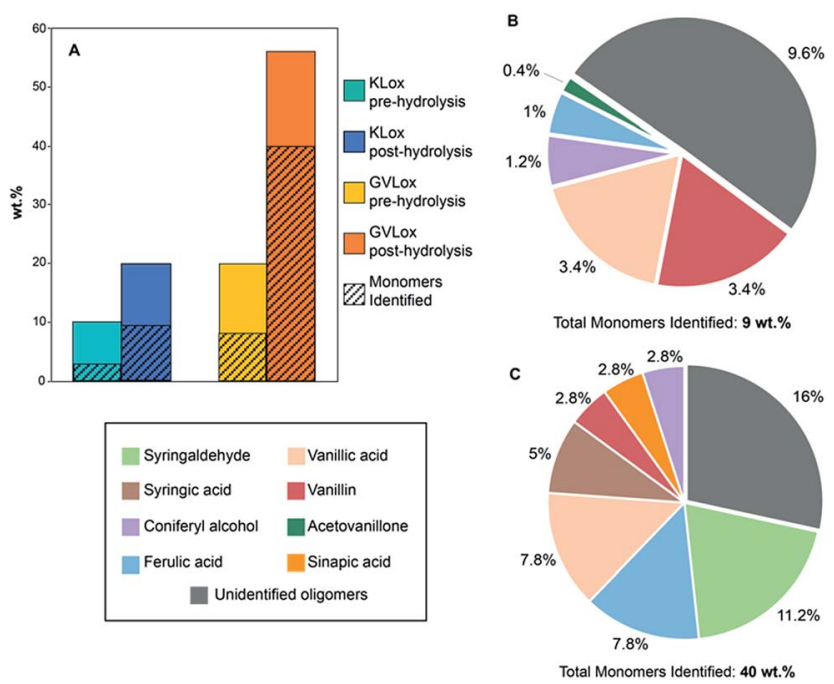

Fig. 5 (A) Percent organic soluble fraction obtained from $\mathrm{KL}_{\mathrm{ox}}$ and $\mathrm{GVL}_{\mathrm{ox}}$ pre- and post-hydrolysis. Oxidized lignin samples $(50 \mathrm{mg}$ ) were dissolved in $0.1 \mathrm{M} \mathrm{NaOH}(5 \mathrm{~mL})$, followed by addition of $1 \mathrm{M} \mathrm{HCl}$ until $\mathrm{pH} 2$ was reached, and were then extracted with EtOAc. For additional details refer to ESI. (B) Yields of monomer products from $\mathrm{KL}_{\mathrm{ox}}$ and (C) $\mathrm{GVL}_{\mathrm{ox}}$ after hydrolysis. Corresponding yields for control experiments (conducted without catalyst) are shown in the ESI. $\dagger$

produce a recalcitrant lignin that is $\mathrm{C}-\mathrm{C}$ cross-linked, and hence difficult to depolymerize. ${ }^{8}$ However, the results obtained with $\mathrm{GVL}_{\mathrm{ox}}$ are significant given that GVL more closely resembles the structure of native lignin than does KL. ${ }^{52}$ Gel permeation chromatography (GPC) revealed two peaks for both $\mathrm{KL}_{\mathrm{ox}}$ and $\mathrm{GVL}_{\mathrm{ox}}$ after hydrolysis (Fig. S9†). The first peak in both chromatograms represent fractions containing high molecular weight oligomers, and the second peak corresponds to low molecular weight components. The high molecular weight region shows a $\sim 3500$ Da decrease in molecular weight for $\mathrm{KL}_{\mathrm{ox}}$ post-hydrolysis while a decrease of $\sim 1000$ Da was observed for $\mathrm{GVL}_{\mathrm{ox}}$ post-hydrolysis. The low molecular weight range shows monomer production for both lignins, however, a significantly higher signal intensity was obtained from $\mathrm{GVL}_{\mathrm{ox}}$ post-hydrolysis compared to $\mathrm{KL}_{\mathrm{ox}}$ post-hydrolysis, consistent with the results previously mentioned in Fig. 5A.

Compound identification and quantification via GC-MS revealed that S- and G-derived carboxylic acids and aldehydes are the most prominent products (Fig. 5B and C). The yield of GC-MS identifiable monomers from GVL totaled $40 \mathrm{wt} \%$, whereas a $10 \mathrm{wt} \%$ yield of GC-MS identifiable monomers was obtained from KL. Among the identified monomers, vanillin, vanillic acid, ferulic acid, and coniferyl alcohol were present from both lignins. Yields of these monomers, except for vanillin, were found to be higher from $\mathrm{GVL}_{\mathrm{ox}}$ than from $\mathrm{KL}_{\mathrm{ox}}$. Sderived products were only obtained from GVL, as the KL used in this work was derived from pine, which consists of almost exclusively $\mathrm{G}$ units, a small amount of $\mathrm{H}$ units, and no $\mathrm{S}$ units. ${ }^{53}$ Notably, the monomers obtained, including vanillin, vanillic acid, and syringaldehyde, are of higher market value than those typically derived from hydrogenative methods of lignin depolymerization..$^{54}$ These monomer yields are the highest reported to date for heterogeneously catalyzed oxidative lignin depolymerization $^{55}$ and approach those reported for the most effective homogenous catalysts. ${ }^{56,57}$ Notably, the lignins employed in the latter case were either extracted enzymatically or via mild acidolysis, which preserves a high fraction of $\beta$-aryl ether linkages. ${ }^{57}$ The fact that we observe a $40 \mathrm{wt} \%$ monomer yield from a lignin that is extracted via a scalable method, utilizing a biomass-derived solvent, renders the $\mathrm{Au} / \mathrm{Li}-\mathrm{Al} \mathrm{LDH}$ catalyst system particularly promising.

\section{Conclusions}

The heterogeneous catalyst $\mathrm{Au} / \mathrm{Li}-\mathrm{Al} \mathrm{LDH}$ showed excellent activity and selectivity in the oxidation of benzylic alcohols using molecular oxygen as the terminal oxidant. XPS data suggest the high activity of this catalyst is facilitated by charge transfer from the basic $\mathrm{Li}-\mathrm{Al} \mathrm{LDH}$ support to the $\mathrm{Au}$ nanoparticles. As evidenced by the model $\beta-\mathrm{O}-4$ linkage dimer oxidation results, our catalytic system was able to oxidatively cleave the linkage after selective benzylic alcohol oxidation, ultimately forming an ester moiety that can be depolymerized via simple hydrolysis. Similarly, NMR data obtained on oxidized kraft lignin $\left(\mathrm{KL}_{\mathrm{ox}}\right)$ and $\mathrm{GVL}$ lignin $\left(\mathrm{GVL}_{\mathrm{ox}}\right)$ showed the disappearance of benzylic alcohol groups, consistent with ester formation. After hydrolysis was performed on oxidized lignin samples, a $40 \mathrm{wt} \%$ yield of aromatic monomers was obtained from $\mathrm{GVL}_{\mathrm{ox}}$, while $\mathrm{KL}_{\mathrm{ox}}$ afforded $10 \mathrm{wt} \%$ monomers. These monomer yields are the highest reported for heterogeneously catalyzed oxidative lignin depolymerization. Based on these results, $\mathrm{Au} / \mathrm{Li}-\mathrm{Al} \mathrm{LDH}$ is identified as a promising catalyst system for lignin valorization to value-added low molecular weight aromatics.

\section{Conflicts of interest}

There are no conflicts to declare.

\section{Acknowledgements}

This research was funded by the National Science Foundation under Cooperative Agreement No. 1355438 and by the Global Bioenergy, Biofuels, and Biorefining network $\left(\mathrm{GB}^{3}-\mathrm{Net}\right)$ supported by the British Council and the Department for Business, Innovation and Skills (BIS). This work was also funded in part by the DOE Great Lakes Bioenergy Research Center (DOE Office of Science BER DE-FC02-07ER64494 and DE-SC0018409). The authors thank Shelley Hopps for performing the XRD measurements and Dr Mark Meier for helpful discussions.

\section{References}

1 R. A. Sheldon, Green Chem., 2014, 16, 950-963.

2 A. J. Ragauskas, G. T. Beckham, M. J. Biddy, R. Chandra, F. Chen, M. F. Davis, B. H. Davison, R. A. Dixon, P. Gilna, M. Keller, et al., Science, 2014, 344, 709.

3 C. R. Brown and R. T. Brown, Why Are We Producing Biofuels?, Brownia LLC, 2012. 
4 J. Kautto, M. J. Realff, A. J. Ragauskas and T. Kässi, BioResources, 2014, 9, 6041-6072.

5 R. Davis, L. Tao, E. C. D. Tan, M. J. Biddy, G. T. Beckham, C. Scarlata, J. Jacobson, K. Cafferty, J. Ross, J. Lukas, et al., NREL/TP-5100-60223 2013.

6 J. Zakzeski, P. C. A. Bruijnincx, A. L. Jongerius and B. M. Weckhuysen, Chem. Rev., 2010, 110, 3552-3599.

7 C. Heitner, D. Dimmer and J. Schmidt, Lignin and Lignans: Advances in Chemistry, CRC Press, 2010.

8 R. Rinaldi, R. Jastrzebski, M. T. Clough, J. Ralph, M. Kennema, P. C. A. Bruijnincx and B. M. Weckhuysen, Angew. Chem., Int. Ed., 2016, 2-54.

9 J.-P. Lange, Catal. Sci. Technol., 2016, 6, 4759-4767.

10 W. Schutyser, T. Renders, S. Van den Bosch, S.-F. Koelewijn, G. T. Beckham and B. F. Sels, Chem. Soc. Rev., 2018, 47, 852908.

11 B. M. Upton and A. M. Kasko, Chem. Rev., 2016, 116, 22752306.

12 H. Lange, S. Decina and C. Crestini, Eur. Polym. J., 2013, 49, 1151-1173.

13 L. Das, P. Kolar and R. Sharma-Shivappa, Biofuels, 2012, 3, 155-166.

14 R. Behling, S. Valange and G. Chatel, Green Chem., 2016, 18, 1839-1854.

15 C. Li, X. Zhao, A. Wang, G. W. Huber and T. Zhang, Chem. Rev., 2015, 115, 11559-11624.

16 O. Deutschmann, H. Knözinger, K. Kochloefl and T. Turek, in Ullmann's Encycl. Ind. Chem., Wiley-VCH Verlag GmbH \& Co. KGaA, 2012, vol. 6, pp. 457-481.

17 J. Mottweiler, M. Puche, C. Räuber, T. Schmidt, P. Concepción, A. Corma and C. Bolm, ChemSusChem, 2015, 8, 2106-2113.

18 H. Deng, L. Lin and S. Liu, Energy Fuels, 2010, 24, 4797-4802.

19 H. Deng, L. Lin, Y. Sun, C. Pang, J. Zhuang, P. Ouyang, Z. Li and S. Liu, Catal. Lett., 2008, 126, 106-111.

20 J. Zhang, H. Deng and L. Lin, Molecules, 2009, 14, 2747-2757.

21 M. R. Sturgeon, M. H. O'Brien, P. N. Ciesielski, R. Katahira, J. S. Kruger, S. C. Chmely, J. Hamlin, K. Lawrence, G. B. Hunsinger, T. D. Foust, et al., Green Chem., 2014, 16, 824-835.

22 J. S. Kruger, N. S. Cleveland, S. Zhang, R. Katahira, B. A. Black, G. M. Chupka, T. Lammens, P. G. Hamilton, M. J. Biddy and G. T. Beckham, ACS Catal., 2016, 6, 13161328.

23 X. Wu, S. Guo and J. Zhang, Chem. Commun., 2015, 51, 63186321.

24 A. Rahimi, A. Azarpira, H. Kim, J. Ralph and S. S. Stahl, J. Am. Chem. Soc., 2013, 135, 6415-6418.

25 J. K. Mobley and M. Crocker, RSC Adv., 2015, 5, 65780-65797. 26 T. Mitsudome, A. Noujima, T. Mizugaki, K. Jitsukawa and K. Kaneda, Adv. Synth. Catal., 2009, 351, 1890-1896.

27 L. M. D. R. S. Martins, S. A. C. Carabineiro, J. Wang, B. G. M. Rocha, F. J. Maldonado-Hodar and A. J. L. Pombeiro, ChemCatChem, 2016, 9, 1211-1221.

28 A. Abad, C. Almela, A. Corma and H. García, Tetrahedron, 2006, 62, 6666-6672.
29 L. C. Wang, Y. M. Liu, M. Chen, Y. Cao, H. Y. He and K. N. Fan, J. Phys. Chem. C, 2008, 112, 6981-6987.

30 J. L. Shumaker, C. Crofcheck, S. A. Tackett, E. SantillanJimenez, T. Morgan, Y. Ji, M. Crocker and T. J. Toops, Appl. Catal., B, 2008, 82, 120-130.

31 P. Zhang, Y. Sui, G. Xiao, Y. Wang, C. Wang, B. Liu, G. Zou and B. Zou, J. Mater. Chem. A, 2013, 1, 1632-1638.

32 C. A. Stowell and B. A. Korgel, Nano Lett., 2005, 5, 12031207.

33 L. Li, L. Dou and H. Zhang, Nanoscale, 2014, 6, 37533763.

34 S. Wang, S. Yin, G. Chen, L. Li and H. Zhang, Catal. Sci. Technol., 2016, 6, 4090-4104.

35 L. Wang, J. Zhang, X. Meng, D. Zheng and F. S. Xiao, Catal. Today, 2011, 175, 404-410.

36 W. Fang, J. Chen, Q. Zhang, W. Deng and Y. Wang, Chem.Eur. J., 2011, 17, 1247-1256.

37 W. Fang, Q. Zhang, J. Chen, W. Deng and Y. Wang, Chem. Commun., 2010, 46, 1547-1549.

38 G. J. Hutchings, in Nanotechnol. Catal., ed. B. Zhou, S. Han, R.Raja and G. A. Somorjai, Springer, New York, NY, 2007, pp. 39-54.

39 M. Haruta, N. Yamada, T. Kobayashi and S. Iijima, J. Catal., 1989, 115, 301-309.

40 T. A. Baker, X. Liu and C. M. Friend, Phys. Chem. Chem. Phys., 2011, 13, 34-46.

41 S. Nishimura, Y. Yakita, M. Katayama, K. Higashimine and K. Ebitani, Catal. Sci. Technol., 2013, 3, 351-359.

42 R. Ma, Y. Xu and X. Zhang, ChemSusChem, 2015, 8, 24-51.

43 J. Long, Q. Zhang, T. Wang, X. Zhang, Y. Xu and L. Ma, Bioresour. Technol., 2014, 154, 10-17.

44 W. Deng, H. Zhang, X. Wu, R. Li, Q. Zhang and Y. Wang, Green Chem., 2015, 17, 5009-5018.

45 L. Hora, V. Kelbichová, O. Kikhtyanin, O. Bortnovskiy and D. Kubička, Catal. Today, 2014, 223, 138-147.

46 J. C. A. A. Roelofs, D. J. Lensveld, A. J. Van Dillen and K. P. De Jong, J. Catal., 2001, 203, 184-191.

47 H. Liu, M. Wang, H. Li, N. Luo, S. Xu and F. Wang, J. Catal., 2017, 346, 170-179.

48 T. Rinesch, J. Mottweiler, M. Puche, P. Concepción, A. Corma and C. Bolm, ACS Sustainable Chem. Eng., 2017, 5, 9818-9825.

49 A. S. K. Tsang, A. Kapat and F. Schoenebeck, J. Am. Chem. Soc., 2016, 138, 518-526.

50 M. Wang, J. Lu, X. Zhang, L. Li, H. Li, N. Luo and F. Wang, ACS Catal., 2016, 6, 6086-6090.

51 J. S. Luterbacher, A. Azarpira, A. H. Motagamwala, F. Lu, J. Ralph and J. A. Dumesic, Energy Environ. Sci., 2015, 8, 2657-2663.

52 J. S. Luterbacher, D. Martin Alonso and J. A. Dumesic, Green Chem., 2014, 16, 4816-4838.

53 S. Constant, H. L. J. Wienk, A. E. Frissen, P. de Peinder, R. Boelens, D. S. van Es, R. J. H. Grisel, B. M. Weckhuysen, W. J. J. Huijgen, R. J. A. Gosselink, et al., Green Chem., 2016, 18, 2651-2665. 
54 J. E. Holladay, J. F. White, J. J. Bozell and D. Johnson, Top Value-Added Chemicals From Biomass, Pacific Northwest Natl. Lab., 2007, vol. 2, p. 87.

55 W. Deng, H. Zhang, X. Wu, R. Li, Q. Zhang and Y. Wang, Green Chem., 2015, 17, 5009-5018.
56 A. Rahimi, A. Ulbrich, J. J. Coon and S. S. Stahl, Nature, 2014, 515, 249-252.

57 A. Das, A. Rahimi, A. Ulbrich, M. Alherech, A. Hussain Motagamwala, A. Bhalla, L. da Costa Sousa, V. Balan, J. A. Dumesic, E. L. Hegg, et al., ACS Sustainable Chem. Eng., 2018, 6, 3367-3374. 